\title{
34 AREITO: A DEVELOPMENT PLATFORM FOR VIRTUAL LEARNING COMMUNITIES
}

\author{
César Garita, Ulises Agüero \\ Costa Rican Institute of Technology, COSTA RICA \{cgarita, uaguero\}@ic-itcr.ac.cr \\ Lorenzo Guadamuz \\ Innova Technology,lguadamuz@innovatechnology.net \\ DOMINICAN REPUBLIC
}

\begin{abstract}
Areito is the name of a Virtual Learning Environment (VLE) that is being set up and used by multiple educational organizations in the Dominican Republic. Through Areito, it is possible to simultaneously create, manage and deploy a large number of Virtual Learning Communities (VLCS) oriented towards diverse aspects of learning processes in education, science and technology. The nature and specific contents of ench VLC are defined by authorized endusers by selecting and configuring collaborative IT tools that best support the social interaction and knowledge exchange between members of a given VLC. This papers provides a general description of Areito and the development of pilot VLCs at educational organizations in the Dominican Republic.
\end{abstract}

\section{INTRODUCTION}

Although there is no formally standardized definition of the Virtual Community (VC) concept, the following description provided by Rheingold is widely cited in many related publications: "Virtual communities are social aggregations that emerge from the Net when enough people carry on public discussions long enough, with sufficient human feeling, to form webs of personal relationships in cyberspace" [1]. Currently, VC environments have become extremely popular and have expanded to many areas including professional, social, educational and entertainment domains. Nevertheless, independently of the main interest or purpose of a given $\mathrm{VC}$, it is important to bear in mind that any $\mathrm{VC}$ is ultimately based on social networks of people that use the $\mathrm{VC}$ environment to maintain and strengthen their interaction through the web. This implies that the success of a VC heavily depends on the extent to which it allows effective sharing and exchange of information to support an underlying social interaction process among people with a specific interest or common goal.

One of the most important application domains of VCs is learning and education. Here, Virtual Learning Communities (VLCs - also referred to as On-line Learning Communities) can be defined as follows: "learning atmospheres, a context providing a supportive system from which sustainable learning processes are gained through a dialogue and collaborative construction of knowledge by acquiring, generating, analyzing and structuring information" [2]. 
According to this approach, the main foundation of VLCs communities lies on the proper exchange of knowledge among their members. In general, knowledge can be either explicit (e.g. organizational documents) or implicit (e.g. tacit experiences and knowledge of people). Normally, members build together the contents of the community instead of just using pre-existing materials. Furthermore, members have as common goal to mutually support each other during the accomplishment of learning activities. In general, the concept of VLC is rather complex since it involves aspects from multidisciplinary areas such as pedagogy, philosophy, sociology, communication and computer science.

In this context, this paper focuses on Areito ${ }^{1}$ - A Virtual Learning Community Environment in the Dominican Republic [3]. Areito is the main component of the Digital Services Platform project of the State Ministry of Higher Education, Science and Technology (SEESCYT) of the Dominican Republic. Areito, by design, is a web portal to create portals with multiple tools available for online information, interaction and collaboration. Areito's portals represent Virtual Learning Environments (VLE) called Virtual Learning Communities (VLC). Here, a VLC is defined as a community of persons and organizations that come together through a web environment with the main purpose of improving learning processes in higher education and research in the Dominican Republic. Thus, a VLC represents a group of persons (e.g. students, teachers, researchers, professionals) and different educational organizations (e.g. universities, ministries, private companies, international organizations) in the Dominican Republic. The term learning is used here as the acquisition of knowledge through formal study and research experiences carried out at university level. Thus, a myriad of VLCs can simultaneously emerge around specific interest topics at universities such as for instance industrial engineering, manufacturing, chemistry, teachers training and nanotechnology, among many others.

The rest of this paper is organized as follows. Section 2 provides a brief introduction to Areito VLC reference model. Section 3 summarizes the analysis phase that led to the identification of the VLC interactive collaboration tools used in this platform. Section 4 includes several platform development and deployment issues regarding actual VLCs in the Dominican Republic. Finally, Section 5 outlines some related conclusions and future work activities.

\section{ARETTO VLC MODEL}

In order to define the VLC model and functional requirements for Areito, many existing related projects, initiatives and resources were analyzed including virtual learning / academic communities ([4],[5],[6]), communities of practice ([7],[8],[9]) and specific virtual environments focusing on social, health-care and rural communities, among others [10],[11],[12]. Furthermore, relevant Collaborative Supported Cooperative Learning (CSCL) tools were studied as well as Learning Management Systems (LMSs) such as Blackboard, Angel and Moodle [13],[14], [15],[16]. After this extensive analysis, we concluded that although there is large number of virtual community initiatives on many different domains, there is still a

\footnotetext{
${ }^{1}$ This project has been developed with funds from the State Ministry of Higher Education, Science and Technology (SEESCYT) of the Dominican Republic through Innova Technology.
} 
tangible need to develop environments focusing on collaborative learning with a strong sense of community. Thus, one of the main distinctive features of Areito is its virtual community approach integrating aspects of VC, CSCL and LMS models. It can be clarified that although Areito is not a course management system, it allows for the creation of VLC with the purpose of supporting coursework. In addition, state-of-the art CSCW reliable software technologies are the foundation of Areito's tools to develop VLC. These community-building tools are fully integrated through best web practices with high productivity and low technical support as design goals.

Furthermore, one of the novel features provided by Areito is the seamless integration of a wide variety of web-based interactive communication tools ranging from basic facilities typically found in VC environments (e.g. chat, mailing lists, instant messaging, discussion board, whiteboard, videoconference, application sharing) to higher-level collaboration tools that are rarely available within these environments, supporting for instance, organization of educational events (e.g. conferences, seminars, talks), digital publications (e.g. informative digital bulletin), knowledge base management, service centers (e.g. helpdesks) and digital markets to exchange services and products. Another major feature of Areito is the fact that VLC design and content management tasks are carried out by administrator users themselves in a flexible and configurable fashion using built-in VLC templates and drag-and-drop facilities for laying out web components on screen. Finally, Areito's end-user interface has been specially designed considering graphical elements closely related to Dominican art and culture in order to achieve an attractive personalized environment for target users.

The rest of this section describes the general reference model for VLCs used in Areito including its target audience, overall structure and typology.

\subsection{Target Audience}

According to the VLC definition given previously in Section 1, the general audience of virtual communities in Areito is composed of the following actors sharing an interest in improving learning processes in the Dominican Republic:

- Instructors and researchers.

- Students.

- Professionals in education.

- Universities and educational centers.

- State Ministry of Higher Education, Science and Technology.

- Public and private enterprises.

- International organizations.

The general audience members or actors were identified based on interviews and general meetings with potential end users from different educational organizations.

Subsets of this list of actors could join up dynamically and create different VLCs with specific goals and purposes. Clearly, the target audience of Areito is extremely large and varied in nature. Therefore, specific key aspects that are usually carefully identified when building a virtual community environment such as audience, purpose, kinds of interactions, duration, policies, IT tools, etc., will ultimately depend on each specific VLC created within Areito. As a result, the VLC environment must support a high degree of flexibility and configurability. 


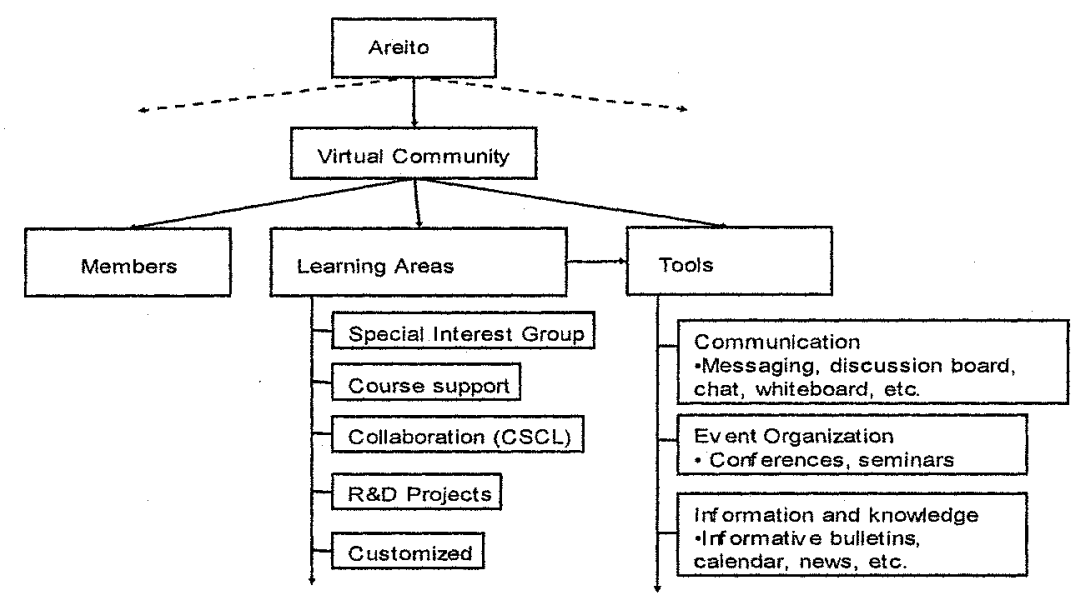

Figure 1 - Areito VLC reference model.

\subsection{VLC Reference Model}

Many related initiatives and projects have proposed reference models for virtual community design (see [17],[18]). In the case of Areito, the proposed VLC reference model is presented in Figure 1. As shown in this figure, Areito is in fact a portal of VLCs that can be applied in different learning scenarios. Each VLC is conceptually composed of a set of members (persons), learning areas and IT tools. Learning areas represent interaction spaces where members can collaboratively exchange and construct knowledge. Examples of learning areas include:

- Special Interest Groups (SIGs): SIGs represent (sub) virtual communities created by members with (more) specific interests within a given VLC.

- Course management: area where members can learn using an approach similar to Course Management Systems (CMS) like Moodle or Blackboard.

- Collaborative learning: area where members interact following a Computer Supported Cooperative Learning (CSCL) approach such as BSCW $[13,19]$.

- Research projects: areas devoted to support collaboration within R\&D projects.

- Customized area: refers to spaces specially designed for other particular purposes depending on specific community needs.

Interactive and collaborative tools in this model can be associated to VLCs and learning areas. These tools will be described later in this paper.

Please notice that the proposed classification of learning areas reflects the fact that one of the main design goals of Areito is to apply an integral approach to support learning scenarios involving aspects from virtual communities, learning management systems and collaborative learning tools as mentioned previously.

\subsection{Typology of VLCs}

VLCs can be classified according to different criteria [2],[18],[20]. In Areito, the classification shown on Table 1 is used, based mainly on the type of activity carried out by members of the community. 
Table 1 - Main types of VLCs in Areito.

\begin{tabular}{|l|l|}
\hline Type & Description \\
\hline $\begin{array}{l}\text { Research, } \\
\text { Innovation } \\
(\mathrm{R}+\mathrm{D}+\mathrm{I}) \text { VLCs }\end{array}$ & $\begin{array}{l}\text { VLCs allow members to focus on interest topics related to } \\
\text { knowledge creation and novel application of existing } \\
\text { technology. Members share a personal interest to contribute } \\
\text { and participate in activities related to knowledge creation. }\end{array}$ \\
\hline $\begin{array}{l}\text { Educational } \\
\text { VLCs }\end{array}$ & $\begin{array}{l}\text { VLCs offer members a context oriented towards educational } \\
\text { learning processes such as pedagogy, academic resources, } \\
\text { instructors training, educational events and students support. }\end{array}$ \\
\hline $\begin{array}{l}\text { Professional } \\
\text { VLCs }\end{array}$ & $\begin{array}{l}\text { VLCs provide an environment in which members can share and } \\
\text { exploit practical experiences and knowledge related with their } \\
\text { profession, e.g. work culture, problem perception, professional } \\
\text { values, best practices and novel trends. }\end{array}$ \\
\hline Interest VLCs & $\begin{array}{l}\text { VLCs gather people that share an interest in a particular subject } \\
\text { or cause, e.g. handling of a certain disease, politics, culture, } \\
\text { law, religion, environment, languages. Participants make an } \\
\text { effort to understand and cooperate with other members. }\end{array}$ \\
\hline Social VLCs & $\begin{array}{l}\text { VLCs based on a network of contacts of individuals with an } \\
\text { interest in social interaction and entertainment. Participants } \\
\text { often sympathize with others very easily. Community } \\
\text { contributes to a sense of group identity and membership }\end{array}$ \\
\hline
\end{tabular}

Please notice that in the above classification, VLC types show a very wide diversity of learning application domains (e.g. VLCs can focus on different areas of science, technology or engineering) and participant members (e.g. members of VLCs can be combinations of educators, students and professionals, among others). This reference typology is useful for end-users in order to better describe the purpose and context of a given VLC and it provides a standard way to classify and access entries of Areito's VLC directory. The proposed typology was validated and applied to actual VLCs suggested by end users.

\section{ANALYSIS OF COLLABORATIVE VLC TOOLS}

Different listings and classifications of ICT tools for VLC support can be found in [21],[22],[23],[24]. These classifications are based on characteristics such as: documentation vs. communication services; synchronous vs. asynchronous tools; interaction possibilities along time and space axes; and so forth.

As a first step to identify functional requirements in terms of communication and collaboration tools for Areito, an extensive survey of existing projects, initiatives and tools was carried out (see Section 2). After this survey, a list of commonly existing features was built and new advanced tools were proposed.

In order to assess the actual usefulness of the identified tools from the targetaudience perspective, a workshop event was organized in which the general model approach of Areito was presented and a questionnaire was applied to more than 20 persons from 13 different universities in the Dominican Republic. The main objective of the questionnaire was to consult, identify and characterize the needs of universities in relation to Areito VLC environment. The questionnaire included items regarding the selection of adequate interactive / collaborative tools for VLCs 
proposed by end users themselves. As a result of this activity, several kinds of tools were identified for later specification and development, as summarized in Table 2.

Table 2 - Summary of Areito interactive and collaborative tools.

\begin{tabular}{|l|l|}
\hline \multicolumn{1}{|l|}{ Basic information / communication tools } \\
\hline Messaging & Email, SMS, instant messaging, presence indicator. \\
\hline Communication & Video conference, chat, whiteboard, forum, blogs, wikis. \\
\hline $\begin{array}{l}\text { Special interest } \\
\text { groups (SIGs) }\end{array}$ & Groups of people created within a VLC around a given subject. \\
\hline $\begin{array}{l}\text { Information } \\
\text { management }\end{array}$ & $\begin{array}{l}\text { Document library, calendar of events, search, news, informational } \\
\text { multimedia elements, subscriptions, RSS feeds, SMS, WAP } \\
\text { services, contextual help. }\end{array}$ \\
\hline Advanced collaboration / interaction tools \\
\hline $\begin{array}{l}\text { Group decision } \\
\text { support }\end{array}$ & $\begin{array}{l}\text { Voting, polls. These tools gather information about the opinion of } \\
\text { persons about a particular statement of questions. }\end{array}$ \\
\hline Event organization & $\begin{array}{l}\text { Support for organization of educational events (conferences } \\
\text { including participant registration, call for papers, paper evaluation). }\end{array}$ \\
\hline Digital market & $\begin{array}{l}\text { Website where offers and demands of services and products are } \\
\text { placed by VLC members. }\end{array}$ \\
\hline Course support & $\begin{array}{l}\text { Website providing facilities for course management (e.g. projects, } \\
\text { assignments, resources, course program, grades). }\end{array}$ \\
\hline Digital bulletin & $\begin{array}{l}\text { Allows creation of bulletin news templates, specification of bulletin } \\
\text { sections and contents, web publishing and distribution. }\end{array}$ \\
\hline Configuration and administration tools \\
\hline VLC management & $\begin{array}{l}\text { Creation of VLCs based on templates, interface design (drag-and- } \\
\text { drop of webparts), access rights definitions, VLC areas subscriptions, } \\
\text { hosting facilities, members profile management, user roles, etc. }\end{array}$ \\
\hline
\end{tabular}

In later cycles of analysis and design, additional advanced tools were identified and developed such as knowledge base manager, service center (helpdesk), real-time forum and draft maker (real-time collaborative text editor).

Besides the identification of the above tools, other functional requirements were considered regarding the following aspects of VLC environments:

- Sociability: this issue involves people, purpose and policies associated with a VLC [25]. In particular, netetiquette policies (behavior) need to be clearly stated [26]. VLC administrators are encouraged to always include a section on community purpose and policies.

- Usability and accessibility: usability refers to user interface considerations including: consistent navigation, familiar language and icons and clear layout design. Accessibility is related to usability issues addressing special characteristics or disabilities of VLC members such as vision problems.

- Aliveness. A key for success in VLCs is "their ability to generate enough excitement, relevance, and value to attract and engage members" [27]. Therefore, the website must always look "alive" and continuously present new contents to users. This is supported in Areito through different ways. For instance, Areito, being organized as a hierarchy of portals, provides mechanisms to effectively make VLC and their activities visible in many levels of the hierarchy and in many ways. Areito's informational multimedia elements adapt to Areito's own interior aliveness to promote VLC's evolution. Namely, VLC 
promotional mini-posters, automatically generated news, interactive informational multimedia elements with subscription modalities (e.g. email, RSS, podcast, SMS), list of on-line users and adaptive user interfaces are examples of means to ensure that VLC evolution is indeed noticeable for end users of Areito.

- Configurability and personalization. The environment should be able to adapt itself according to user preferences and profile information, instead of making users adapt to the environment. In addition, users should be able to easily select and configure tools that best suit their interaction needs.

\section{DEVELOPMENT AND DEPLOYMENT ISSUES}

The Areito portal has been developed using Microsoft SharePoint Services technology as support platform [28]. Through SharePoint, a set of basic collaboration and communication services are available in order to build organizational websites. Among the collaboration features of this product, we can mention: Microsoft Office integration, document collaboration and user presence indication. Other technical features include: ASP.NET extensibility, website templates (websites can be saved as templates for distribution and further instantiation), web parts (reusable components) and maintenance-free site development. Based on this platform, Areito communication and collaboration tools shown on Table 2 were developed or integrated.

Once the selected tools were developed and tested, specific VLC templates were designed in order to better assist end users with VLC creation and configuration tasks. Namely, VLC templates allow the creation of entire websites and associated tools using preexisting definition files. These templates represent "emerging use patterns" of Areito communication and collaboration tools. Moreover, any VLC website can in turn be saved as a template for future reutilization. Examples of developed VLC templates are: basic Areito VLC (VLC with main tools), Areito Portal (website with a VLC directory), and VLC for course support.

A snapshot of Areito portal (in Spanish) is shown on Figure 2 (see also [3]). The top section of the website includes the following elements: a banner specially designed with Dominican Republic art motifs and pictures, search toolbar, contextual help link, hot links (e.g. create VLC) and user identification. Below the top section, the three main layout areas are: configurable quick-access menu area (left), relevant information and knowledge exchange area (middle) and general information area (e.g. recent news, contact information, presence indicator) to the right. The middle area includes a welcome and introduction section to the portal, a directory of specific VLCs created within Areito, as well as general discussion section and on-line polls. Furthermore, the main menu on the leftmost area gives access to other relevant information components of the portal, such as calendar of events, document library, FAQs, digital bulletin and administration and configuration tools. Interface elements (web parts) on any area can be moved to any position on screen by a drag-and-drop facility available to administrators in pagedesign mode. 


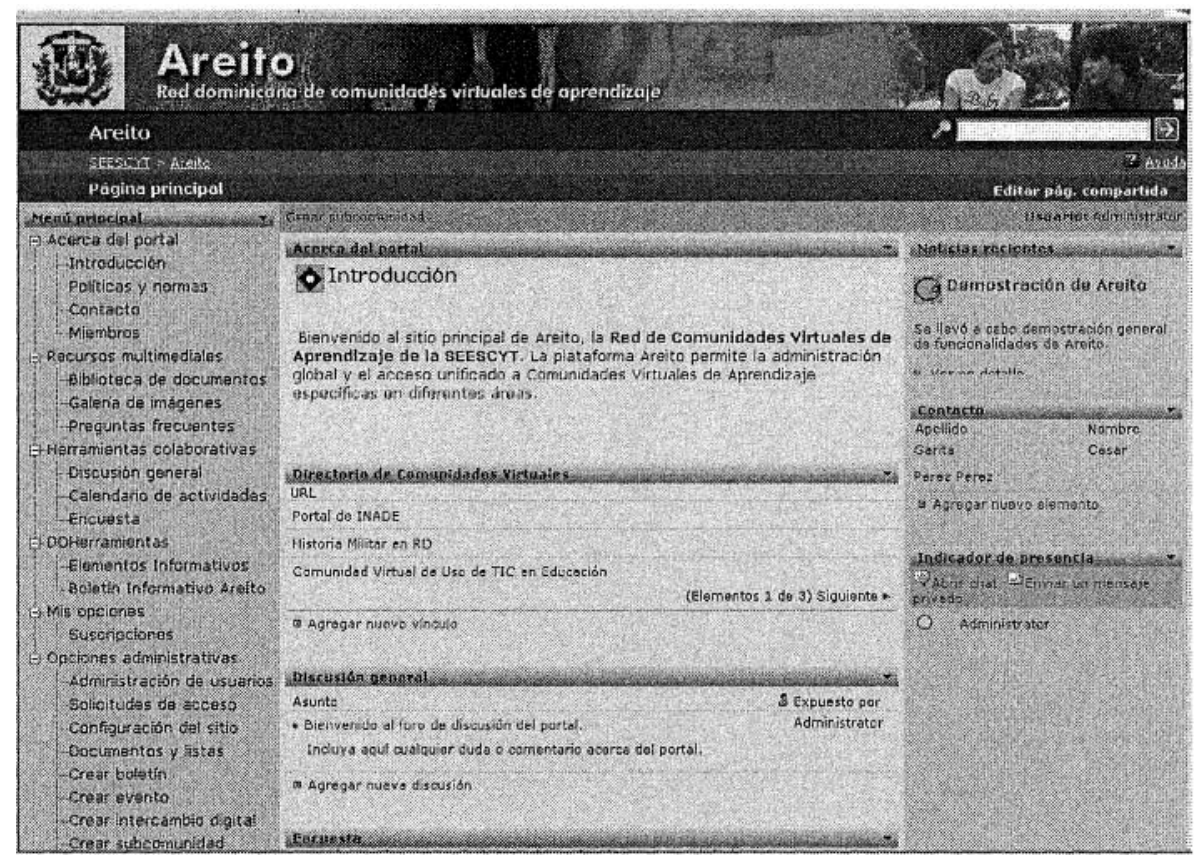

Figure 2 - Screenshot of Areito Virtual Learning Communities Portal.

The Areito VLC directory (central position on screen) contains entries with URLs to actual VLCs hosted for different universities and educational organizations in the Dominican Republic. Examples of current VLCs in this directory include specific communities on the following subjects: ICT Use in Education; Agroalimentary, Biotechnology and Business Sciences; National Defense Academy; Websites Visibility; English Teaching; Education on AIDS Issues; and Presidential Forum for Educational Excellence; among others. All these VLCs have been developed based on templates and make intensive use of collaboration tools such as digital bulletin, event organization and digital market, described earlier in this paper. It is expected that with adequate training and support, end-users will be able to actively create and cultivate many other VLCs themselves.

It is important to mention that since Areito was made available in January 2006, VLCs have recently been launched for end-user groups and are at an early "nurturing" stage. In this sense, they represent pilot VLCs that are starting up and that will soon provide valuable feedback for platform developers and managers. All VLCs were identified or proposed by end-users during workshop events or individual meetings. For each VLC a "route map" has been defined in collaboration with end users in order to have a customized VLC development and sustainability plan including training workshops, special VLC content uploading, VLC follow-up events, end-users group meetings and promotion of new VLCs. A route map can be seen as a graph containing information about activities, goals, deadlines, evaluation criteria, dependencies, required resources and responsible persons.

An example of a particular VLC is provided in Figure 3. Becas Internacionales is a VLC about international scholarship opportunities for students and professors of the Dominican Republic. This is a community where the Government publishes 


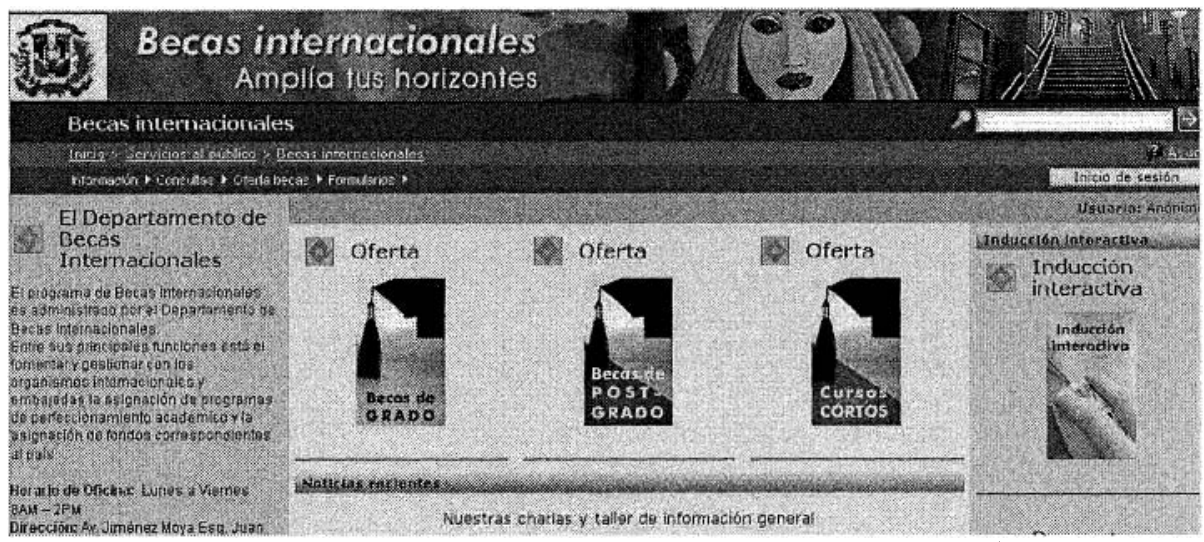

Figure 3 - Screenshot of International Scholarships VLC.

available options and community members search for those options effectively. Additionally, the community serves as a training site for prospective scholarship recipients, and as a Service Center for real-time communication between students and professors and the people knowledgeable about scholarships.

Interested parties can apply online for scholarships, interactively query the scholarship system about the current status of their applications, use forum-like tools to ask questions and receive answers asynchronously, download relevant documents and application forms, review available scholarship options from international organizations and subscribe to receive electronic bulletins periodically. People can also query the international scholarship recipients database to find out about previous recipients and their universities.

For these tasks, Areito provides community administrators and users with a number of innovative tools to create bulletins, to organize relevant events, to create scholarships markets where options are published, interests are expressed and matches are automatically ranked, to maintain multimedia information elements such as news, to subscribe to SMS, PODCAST, e-mail and RSS information services, to organize interactive forums, to cooperate in the development of documents, to create and maintain contact lists, scholarship lists and much more. Imagination is the limit to the members of the Becas Internacionales VLC.

\section{CONCLUSIONS AND FUTURE WORK}

The Areito environment introduced in this paper represents an advanced platform for creation, development and management of Virtual Learning Communities in the Dominican Republic. Among the main distinctive features of Areito, we can summarize the following: i) use of an integral collaborative learning approach merging aspects of VCs, CSCL y LMS models; ii) wide variety of advanced interactive collaboration tools readily available; and iii) highly flexible and configurable management of VLCs and their contents.

Since launching of the platform has recently taken place, it is necessary to further assess and evaluate end-users perspective and feedback on daily usage and proper evolution of VLCs in Areito. In particular, more work is due regarding VLC design and cultivation guidelines, intensive training workshops and follow-up 
events. Future work also includes development of more tools to further assist course instruction activities. There are also plans to exploit Areito facilities to host VLCs for educational organizations from other Latin American countries besides the Dominican Republic. Development of an English version of Areito should also be considered.

\subsection{Acknowledgments}

The authors of this paper wish to acknowledge the work of Areito developers team as well as valuable inputs from educational organizations in the Dominican Republic.

\section{REFERENCES}

1. H. Rheingold, The virtual community: homesteading on the electronic frontier: Addison-Wesley, 1993.

2. U. Carlen, "Typology of Online Learning Communities", presented at First International Conference on NetLearning2002, Ronneby, Sweden, 2002.

3. Areito, "Areito - Dominican Network of Virtual Learning Communities", http//www seescyt net/areito, 2006.

4. Tappedln, "TappedIn Website", http://tappedin.org/, 2005.

5. RedIris, "RedIris Website", hitp:/www rediris, es/rediris/, 2005.

6. S. Barab, R. Kling, and J. Gray, "Designing for Virtual Communities in the Service of Learning": Cambridge University Press, 2004, pp. 16-52.

7. Tomoye, "Tomoye Website", http://www tomoye com, 2005.

8. VEForum, "VE Forum Website", http://www ve-forim.org, 2005.

9. Knowledgeboard, "Knowledgeboard Website", http:/www. knowledgeboard.com, 2005.

10. TeleCARE, "TeleCARE website", http://www uninova.pt/-telecarel, 2005.

11. TARAhaat, "TARAhaat website", hitt://www.tarahaat.com/tara/home, 2005.

12. Orkut, "Googie Orkut", http://www.orkut.com, 2005.

13. EuroCSCL, "Euro CSCL website", http///www euro-cscl.org/, 2005.

14. Blackboard, "Blackboard website", http:/www.blackboard com, 2006.

15. Angel, "Angel Learning website", http://www. cyberlearninglabs.com/, 2005.

16. Moodle, "Moodle website", http://moodle.org/, 2005.

17. S. Seufert, U. Lechner, and K. Stanoevska, "A Reference Model for Online Learning Communities", presented at 11 th Annual International Information Management Association Conference IMA2000 , Seattle, Washington, 2000.

18. R. Luppicini, "Categories of Virtual Learning Communities for Educational design", The Quarterly Review of Distance Education, vol. 4, pp. 409-416, 2003.

19. Synergeia, "Synergeia website", hitp://bscl.fit.fraunhofer.del, 2005.

20. M. Riel and L. Polin, "Virtual Learning Communities - Common Ground and Critical Differences in Designing Technical Environments", in Designing for Virtual Communities in the Service of Learning, S. Barab, R. Kling, and J. Gray, Eds.: Cambridge University Press, 2004, pp. 16-52.

21. Fullcirc, "Online Community Toolkit", http://fullcirc com/community/communitymanual hthm, 2004.

22. M. Pazos, A. Pérez, and J, Salinas, "Comunidades Virtuales: de las listas de discusión a las comunidades de aprendizaje", 2002.

23. E. Wenger, N. White, J. Smith, and K. Rowe, "Technology for communities", in CEFRIO Book Chapter, 2005.

24. H. Afsarmanesh, V. Guevara, and L. O. Hertzberger, "Virtual Community Support in TeleCARE", presented at PRO-VE 03, 4th IFIP Working Conference on Virtual Enterprises, Lugano, Switzerland, 2003.

25. J. Preece, Online Communities - Designing Usability, Supporting Sociability: John Wiley \& Sons, 2000.

26. J. Preece, C. Abras, and D. Maloney-Krichmar, "Designing and evaluating online communities: research speaks to emerging practice", Int. J. Web Based Communities, vol. 1, 2004.

27. E. Wenger, Cultivating Communities of Practice: Harvard Business School, 2002.

28. Microsoft, "SharePoint Technology", hittp://www. microsoft com/sharepoint/default.mspx, 2003. 